\title{
CONTROL DE CONVENCIONALIDAD EN LOS JUICIOS DE DIVORCIO NECESARIO DEL ESTADO DE TABASCO
}

\author{
CONVENTIONAL CONTROL IN THE TRIALS OF NECESSARY DIVORCE FROM \\ THE STATE OF TABASCO
}

\author{
Jesús Manuel Hernández-Jiménez ${ }^{1}$ * (iD). \\ 1. Escuela Judicial del Estado de Tabasco, México.je_manuel_5@hotmail.com \\ * Autor de correspondencia: Adriana de-Jesús Rodríguez-Ramos, correo electrónico: je_manuel_5@hotmail.com
}

\section{RESUMEN}

En el presente artículo se analiza la problemática del artículo 272 del Código Civil en el Estado de Tabasco, en razón que el mismo señala ciertas hipótesis o causales, las cuales se tiene que acreditar o justificar para que proceda el juicio de divorcio necesario en el Estado, a la luz que diversos tratados internacionales de la cual es parte nuestro país, señalan que toda persona tiene derecho a la libertad, así como al reconocimiento de su personalidad jurídica, por consiguiente existe la obligación a las autoridades judiciales de realizar el control de convencional, y en la cual los jueces locales no se encuentran facultados expresamente para determinar la inconstitucionalidad de una norma y por ende para hacer una declaración general sobre la invalidez de aquellas normas que consideren contrarias a los derechos humanos contenidos en la constitución y los tratados internacionales como sucede en la vía de control directa establecidas expresamente en los artículos 103, 107 y 105 de la Constitución. De ahí la importancia del control de convencional en los jueces locales en el juicio de divorcio necesario.

Palabras clave: Control de convencionalidad; implicación de la ley en procedimiento de divorcio necesario; jueces locales.

Cómo citar:

Hernández-Jiménez, Jesús Manuel. (2021). Control de convencionalidad en los juicios de divorcio necesario del estado de Tabasco. Revista de Investigaciones Universidad del Quindio, 33(S2), 198-206. https://doi.org/10.33975/riuq.vol33nS2.632 


\begin{abstract}
In this article the problem of the 272 Civil Code law from Tabasco is analyzed. It states certain hypotheses or causes, which have to be accredited or justified to proceed with the necessary divorce in the state. Due to the part that our country takes in international treaties, it is pointed out that every person has the right of freedom, as well as the acknowledgement of his/her legal personality. Hence the obligation of the legal authorities of performing the conventional control. It also mentions that local judges are not fully capable of determining the unconstitutionality of a norm therefore making a general statement about the human rights established in the constitution and the international treaties. As it happens in the direct control line, widely expressed in the laws 103, 107, and 105 in the constitution. On these grounds the importance of the conventional control relies on the trials of necessary divorce.
\end{abstract}

Keywords: Conventional Control; needed divorce procedure.

\title{
INTRODUCCIÓN
}

Nuestra Legislación Civil en el Estado de Tabasco, indica que las partes en un juicio de divorcio necesario, pueden comparecer ante el organo jurisdiccional correspondiente para efectos de ejercer dicho derecho tutela en la referida ley, empero para efectos que el mismo sea procedente se deberá justificar o creditar las causales que señala el artículo 272 del Código Civil en el Estado de Tabasco, es decir de las fracciones de la I a la XIX, por lo que en muchas ocasiones justificar las mismas implica un impedimiento durante el desarrollo del proceso, toda vez que si bien es cierto las mencionadas causales pudieron darse durante el matrimonio, tambien lo es que comprobarlo implica una carga procesal bastante complicada, por la naturaleza de la causal que se haya dado.

Por lo que partiendo del punto de vista que los derechos fundamentales de las personas que se encuentran contempladas en la Constitución Politica de los Estados Unidos Mexicanos, y en el caso concreto tales como toda persona tiene derecho a la libertad del libre desarrollo, así como el reconocimiento de su personalidad jurídica, las mismas se tienen que hacer valer en todo momento, es por eso que los jueces locales juegan un papel muy importante en el sentido que tienen que hacer valer los derechos humanos ante cualquier procedimiento judicial que se ventilen en la jurisdicción que les corresponda.

En ese contexto, existe la obligación de hacer valer el control de convencional y constitucionalidad, antes los diversos organos juridiccionales, incluyendo a los Jueces locales, aún y cuando no se encuentren facultado para ello.

\section{METODOLOGÍA}

Este artículo señala aportaciones importantes para efectos de hacer valer los derechos humanos contemplados en la Constitución Policita de los Estados Unidos Mexicanos, así como en los tratados internacionales de los cuales nuestro país de forma parte, ante un procedimiento judicial previamente establecido en la norma local, el cual requiere de forma obligatoria que se cumplan con ciertos requisitos contrarios a dichos derechos fundamentales.

Por lo que el presente artículo se divide en cuatro apartados, para su desarrollo, se divide en cuatro 
apartados: en el primero referente al derecho a la tutela judicial efectiva; en el segundo a la jurisprudencia de los Tribunales Internacionales de Derechos Humanos respecto de convencional de los tratados internacionales y de constitucionalidad; en el tercero la inaplicación del artículo 272 del Código Civil vigente en el Estado de Tabasco en los procedimientos de divorcio necesario, y por último se refiere a las propuestas del tema. La revisión de la literatura del presente artículo se integró con material diverso jurídico, entre los que podemos citar: la Legislación Sustantiva Civil en vigor del Estado de Tabasco; así como de jurisprudencia de los Tribunales Internacionales de Derechos Humanos, Constitución Política de los Estados Unidos Mexicanos. Otorgando una visión sobre la inaplicabilidad de los artículos en contra de los tratados internacionales y la misma Constitución Federal.

\section{RESULTADO}

\section{Derecho a la Tutela Judicial Efectiva.}

Es preciso señalar que el artículo 17 de la Constitución Política de los Estados Unidos Mexicanos, contempla el derecho a la tutela judicial efectiva, que puede definirse como el derecho público subjetivo que toda persona tiene, dentro de los plazos y términos que fijen las leyes, para acceder de manera expedita a tribunales independientes e imparciales, a plantear una pretensión o a defenderse de ella, con el fin de que, a través de un proceso en el que se respeten ciertas formalidades, se decida sobre la pretensión o la defensa y, en su caso, se ejecute esa decisión.

Es el derecho que tiene toda persona de acudir a los Tribunales para que se administre justicia, tal como de igual forma lo señalan los artículos 1, 14, 16, y 17 de la mencionada Constitución, en relación con el numeral 8 de la Convención Americana sobre Derechos Humanos.

Máxime que el artículo 25 de la Convención Americana sobre Derechos Humanos prevé que todo individuo tiene derecho a un recurso sencillo y rápido, ambos preceptos consagran el derecho fundamental de acceso a la justicia o tutela judicial efectiva.

De ahí, que en los juicios de divorcio necesario señalado en nuestra legislación civil en el Estado, deberá aplicarse los diversos tratados internaciones y lo señalado en nuestra constitución, donde en primer término deberá velar por los derechos humanos de las personas, tales como el derecho a la libertad de la personalidad, pues ella no sería efectiva si se limitara al solo acceso en cuanto a que se tenga que justificar o acreditar las causales que se encuentran contempladas en artículo 272 del La Ley Subjetiva Civil en vigor en el estado de Tabasco. El juez no solo es el que juzga, sino también el que manda pues es aquél cuyo juicio tiene la eficacia del mandato.

La Suprema Corte de Justicia de la Nación emitió un pronunciamiento, en el sentido de que la tutela judicial efectiva, consagrada como derecho humano en los artículos 17 de la Constitución Política de los Estados Unidos Mexicanos y 8, numeral 1 y 25, numeral 1, de la Convención Americana sobre Derechos Humanos, en su vertiente de recurso efectivo, implica la obligación para los tribunales de resolver los conflictos que se les plantean sin obstáculos o dilaciones innecesarias y evitando formalismos o interpretaciones no razonables que impidan o dificulten el enjuiciamiento de fondo y la auténtica tutela judicial, por lo que los órganos encargados de administrar justicia, al interpretar los requisitos y las formalidades procesales legalmente previstos, deben tener presente la ratio de la norma para evitar que los meros formalismos impidan un enjuiciamiento de fondo del asunto, tal como lo es en caso concreto del artículo 272 del Código Civil en vigor en el estado, el cual establece 
que para su procedencia se tienen que acreditar obligatoriamente ciertas causales que se encuentran señaladas en el mismo, con llevando con ella una limitación a la tutela efectiva.

Por consiguiente es de señalar que la justicia no sería efectiva si una ley local contradice a los deviseros tratados internacionales o nuestra carta magna, por lo que en el presente supuesto se estaría limitando el acceso a la tutela efectiva, pues una ley deberá ser inaplicable en el caso concreto, en virtud que no puede afectar un derecho humano consagrado en nuestra carta magna.

\section{Aplicación del Control de Convencionalidad en los Juicios de Divorcio Necesario.}

Es de señalar que el acreditar o justificar alguna de las causales por el cual se promueve el juicio de divorcio necesario en nuestra entidad, que señala el artículo 272 del Código Civil en vigor en el Estado, en muchas ocasiones es complicado o difícil de acreditar la misma, por ejemplo acreditar el causal de "el adulterio debidamente probado de unos de los conyugues", por lo que en el presente supuesto es casi imposible demostrar dicha causal, toda vez que tendrías que presentar prueba plena al Juzgador para en este caso en concreto acreditar que realmente hubo adulterio.

Por lo que, atendiendo a lo antes manifestado, es de señalar que nuestra carta magna en sus artículos 1o y 133 de la Constitución Política de los Estados Unidos Mexicanos, y lo establecido en la Tesis Jurisprudencial número IV.2o.A. J/7 (10a.), Décima Época, Gaceta del Semanario Judicial de la Federación, Libro 1, Diciembre de 2013, Tomo II, Página: 933, Registro IUS número 2005056, con el rubro: CONTROL DE CONVENCIONALIDAD. ES UNA OBLIGACIÓN INELUDIBLE DE LA AUTORIDAD JURISDICCIONAL EJERCERLO, AUN DE OFICIO, CUYO INCUMPLIMIENTO VULNERA EL MANDATO CONSTITUCIONAL DE PROTEGER Y GARANTIZAR LOS DERECHOS HUMANOS Y COMPROMETE LA RESPONSABILIDAD INTERNACIONAL DEL ESTADO MEXICANO EN SU CONJUNTO. Queda establecida la obligación que todas las autoridades (jueces federales y locales) en el ámbito de sus respectivas competencias, tienen de promover, respetar, proteger y garantizar los derechos humanos de conformidad con los principios de universalidad, interdependencia, indivisibilidad y progresividad y a preferir los derechos humanos contenidos en la Constitución y los Tratados Internacionales aun a pesar de las disposiciones en contrario establecidas en cualquier norma inferior.

Cabe señalar, que si bien los jueces locales no se encuentran facultados expresamente para determinar la inconstitucionalidad de una norma y por ende para hacer una declaración general sobre la invalidez de aquellas normas que consideren contrarias a los derechos humanos contenidos en la constitución y los tratados internacionales como sucede en la vía de control directa establecidas expresamente en los artículos 103, 107 y 105 de la Constitución; sí están obligados a dejar de aplicar estas normas inferiores dando preferencia a los contenidos de la Constitución y de los tratados internacionales.

Sustenta lo anterior las tesis P. LXX/2011 (9a.), Décima Época, Semanario Judicial de la Federación y su Gaceta, Libro III, Diciembre de 2011, Tomo 1, Página: 557, Registro IUS número 160480. Con el rubro y texto siguiente: “...SISTEMA DE CONTROL CONSTITUCIONAL EN EL ORDEN JURÍDICO MEXICANO. Actualmente existen dos grandes vertientes dentro del modelo de control de constitucionalidad en el orden jurídico mexicano, que son acordes con el modelo de control de convencionalidad ex officio en materia de derechos humanos a cargo del Poder Judicial. En primer término, el control concentrado en los órganos del Poder Judicial de la Federación con vías directas de control: acciones de inconstitucionalidad, controversias constitucionales y amparo directo e indirecto; 
en segundo término, el control por parte del resto de los jueces del país en forma incidental durante los procesos ordinarios en los que son competentes, esto es, sin necesidad de abrir un expediente por cuerda separada. Ambas vertientes de control se ejercen de manera independiente y la existencia de este modelo general de control no requiere que todos los casos sean revisables e impugnables en ambas. Es un sistema concentrado en una parte y difuso en otra, lo que permite que sean los criterios e interpretaciones constitucionales, ya sea por declaración de inconstitucionalidad o por inaplicación, de los que conozca la Suprema Corte para que determine cuál es la interpretación constitucional que finalmente debe prevalecer en el orden jurídico nacional. Finalmente, debe señalarse que todas las demás autoridades del país en el ámbito de sus competencias tienen la obligación de aplicar las normas correspondientes haciendo la interpretación más favorable a la persona para lograr su protección más amplia, sin tener la posibilidad de inaplicar o declarar su incompatibilidad...”.

Por lo que para mayor abundancia a lo antes indica, se cita la Tesis P. LXVII/2011(9a.), Décima Época, Semanario Judicial de la Federación y su Gaceta, Libro III, Diciembre de 2011, Tomo 1, Página: 535, Registro IUS número 160589, con el rubro y texto siguiente: “...CONTROL DE CONVENCIONALIDAD EX OFFICIO EN UN MODELO DE CONTROL DIFUSO DE CONSTITUCIONALIDAD. De que se desprende que conformidad con lo previsto en el artículo 10. de la Constitución Política de los Estados Unidos Mexicanos, todas las autoridades del país, dentro del ámbito de sus competencias, se encuentran obligadas a velar no sólo por los derechos humanos contenidos en la Constitución Federal, sino también por aquellos contenidos en los instrumentos internacionales celebrados por el Estado Mexicano, adoptando la interpretación más favorable al derecho humano de que se trate, lo que se conoce en la doctrina como principio pro persona. Estos mandatos contenidos en el artículo 1o. constitucional, reformado mediante Decreto publicado en el Diario Oficial de la Federación de 10 de junio de 2011, deben interpretarse junto con lo establecido por el diverso 133 para determinar el marco dentro del que debe realizarse el control de convencionalidad ex officio en materia de derechos humanos a cargo del Poder Judicial, el que deberá adecuarse al modelo de control de constitucionalidad existente en nuestro país. Es en la función jurisdiccional, como está indicado en la última parte del artículo 133 en relación con el numeral 1o. Constitucionales, en donde los jueces están obligados a preferir los derechos humanos contenidos en la Constitución y en los tratados internacionales, aun a pesar de las disposiciones en contrario que se encuentren en cualquier norma inferior.

Por lo que partiendo de ese punto de vista, las autoridades judiciales en cualquier ámbito de su competencia, se encuentra obligado a respetar los derechos humanos, en los términos y forma señalado con anterioridad, para efectos de garantizar el derecho de libre personalidad estipulada en nuestra carta magna, ejerciendo el control de convencional.

\section{Inaplicación del artículo 272 del Código Civil en el Estado de Tabasco.}

Es necesario indicar que si bien los jueces no pueden hacer una declaración general sobre la invalidez o expulsar del orden jurídico las normas que consideren contrarias a los derechos humanos contenidos en la Constitución y en los tratados (como sí sucede en las vías de control directas establecidas expresamente en los artículos 103, 105 y 107 de la Constitución), por consiguiente sí están obligados a dejar de aplicar las normas inferiores dando preferencia a las contenidas en la Constitución y en los tratados en la materia...".

En ese sentido dicha aplicación de la ley o norma contrario a los diversos tratados internacionales 
y a la Constitución Federal, deberá efectuarse por los jueces locales, en los términos de la tesis, P. LXIX/2011(9a.), Décima Época, Semanario Judicial de la Federación y su Gaceta, Libro III, Diciembre de 2011, Tomo 1, Página: 552, Registro IUS número 160525. Sustentada con el rubro: “... PASOS A SEGUIR EN EL CONTROL DE CONSTITUCIONALIDAD Y CONVENCIONALIDAD EX OFFICIO EN MATERIA DE DERECHOS HUMANOS, por lo que se establece que el Poder Judicial al ejercer un control de convencionalidad ex officio en materia de derechos humanos, deberá realizar los siguientes pasos: a) Interpretación conforme en sentido amplio, lo que significa que los jueces del país -al igual que todas las demás autoridades del Estado Mexicano-, deben interpretar el orden jurídico a la luz y conforme a los derechos humanos reconocidos en la Constitución Federal y en los Tratados Internacionales en los cuales el Estado Mexicano sea parte, favoreciendo en todo tiempo a las personas con la protección más amplia; b) Interpretación conforme en sentido estricto, lo que significa que cuando hay varias interpretaciones jurídicamente válidas, los jueces deben, partiendo de la presunción de Constitucionalidad de las leyes, preferir aquella que hace a la ley acorde a los derechos humanos reconocidos en la Constitución y en los Tratados Internacionales en los que el Estado Mexicano sea parte, para evitar incidir o vulnerar el contenido esencial de estos derechos; y, c) Inaplicación de la ley cuando las alternativas anteriores no son posibles. Lo anterior no afecta o rompe con la lógica de los principios de división de poderes y de federalismo, sino que fortalece el papel de los jueces al ser el último recurso para asegurar la primacía y aplicación efectiva de los derechos humanos establecidos en la Constitución y en los Tratados Internacionales de los cuales el Estado Mexicano es parte..."

Expuesto lo anterior, los diversos tribunal del país en el ámbito de sus competencias y en especial los locales, procederán a dar cumplimiento a las exigencia de los artículos 1 y y 133 de la Constitución política de los estados Unidos Mexicanos, es decir, a ejercer ex officio el control de convencionalidad a efecto de poder determinar la afectación o no de algún derecho humano reconocido en la constitución federal y los tratados internacionales de los que nuestro país es parte.

En ese contexto se tiene, que en el artículo 256 del Código Civil vigente en el Estado, dispone que el divorcio disuelve el vínculo matrimonial y deja a quienes fueron cónyuges en aptitud de contraer otro.

Por otra parte en el artículo 272 del citado ordenamiento legal, se establecen las diferentes causas por las que se puede disolver el vínculo matrimonial.

De lo anterior, se obtiene que el divorcio necesario en nuestra entidad deberá ser solicitada en relación a las causales establecidas en el artículo 272 del Código Civil referido, y del criterio sustentado en la tesis jurisprudencial número VI.2o. J/183, Octava Época, Semanario Judicial de la Federación, Tomo IX, Marzo de 1992, Página: 95, Registro IUS número 220014. Sustenta con el rubro y texto siguiente: DIVORCIO. LAS CAUSALES DEBEN PROBARSE PLENAMENTE; que señala que la institución del matrimonio es de orden público, por lo que la sociedad está interesada en su mantenimiento y sólo por excepción la ley permite que se rompa el vínculo matrimonial; por lo tanto, tratándose de divorcios necesarios es indispensable que la causal o causales invocadas queden plenamente probadas.

Como en la Legislación Civil del Estado de Tabasco, especialmente en los apartados que normalizan el derecho familiar, no regula en ninguna de sus partes el divorcio encausado o por voluntad unilateral de las partes; y siendo que acorde a lo previsto en el artículo 19 del Código Civil vigente en el Estado, el silencio, obscuridad o insuficiencia de la ley, no autoriza a los jueces para dejar de resolver una controversia que ante ellos sea planteada. Por ello los tribunal locales debe analizar dichos juicios a la 
luz de los derechos humanos consagrados en la Constitución y los tratados internacionales de los que México es parte.

Ahora bien, es de hacer notar, que el Código Civil vigente en el Estado de Tabasco, no define lo que es el matrimonio, sin embargo éste debe entenderse como la unión voluntaria y libre de un hombre y una mujer, con igualdad de derechos y obligaciones.

Es de hacer notar también que el matrimonio surge a la vida jurídica por virtud de la decisión libre de los contrayentes, y se extingue por las causas que señalan los artículos 230, 256 del Código Civil en vigor, como es por nulidad, el divorcio o la muerte o presunción de ésta, de uno de los cónyuges.

Los numerales 1, 2, 3, 6, 12 y 25 de la Declaración Universal de los Derechos Humanos, 1, 2, 3, 5 y 11 de la Convención Americana sobre Derechos Humanos y 3, 16, 17 y 23 del Pacto Internacional de Derechos Civiles y Políticos, reconocen que toda persona tiene derecho a la libertad, así como al reconocimiento de su personalidad jurídica y que nadie podrá ser objeto de injerencias arbitrarias en su vida privada, teniendo el derecho a la protección de la ley contra tales injerencias o ataques, esto es, reconocen una superioridad de la dignidad humana.

Por su parte el Pleno de la Suprema Corte de Justicia de la Nación, al emitir la tesis P. LXVI/2009, publicada en el Semanario Judicial de la Federación y su Gaceta, Novena Época, Tomo XXX, diciembre de 2009, página 7, de rubro: "DERECHO AL LIBRE DESARROLLO DE LA PERSONALIDAD. ASPECTOS QUE COMPRENDE.”, estableció que de la dignidad humana como derecho fundamental, derivan todos los demás derechos, en cuanto son necesarios para que el hombre desarrolle integralmente su personalidad, como el derecho al estado civil de las personas, pues el individuo tiene derecho a elegir, en forma libre y autónoma, su proyecto de vida, la manera en que logrará las metas y objetivos que, para él, son relevantes; así, precisó que el derecho al libre desarrollo de la personalidad comprende, entre otras, la libertad de contraer matrimonio o de no hacerlo, pues es un aspecto que forma parte de la manera en que el individuo desea proyectarse y vivir su vida y que, por tanto, sólo él puede decidir en forma autónoma la decisión de permanecer o no unido en matrimonio.

Atento a lo anterior, y toda vez que la legislación civil del Estado de Tabasco, conforme al tema que se analiza, no permite una posible interpretación conforme a los Derechos Humanos que haga posible el divorcio incausado o por voluntad unilateral de uno solo de los cónyuges, pues como se dijo esta legislación no regula nada conforme a este tipo de divorcio, dado que solo permite la disolución del vínculo matrimonial por mutuo consentimiento de los consortes o mediante la comprobación de cualquiera de las causales previstas en el artículo 272 del Código Civil citado.

Por lo que, las autoridades locales en el ámbito de su competencia en especial del Estado de Tabasco, deberá de considerar que los artículos 272 del Código Civil, 501 y 505 del Código de Procedimientos Civiles ambos ordenamientos vigente en el Estado, al exigir la demostración de determinada causa de divorcio como única forma para lograr la disolución del vínculo matrimonial, cuando no existe consentimiento mutuo de los contrayentes para divorciarse, y establecer que el divorcio solo podrá demandarse por el cónyuge que no haya dado causa a él y que deberá tramitarse conforme a las reglas establecidas para el juicio ordinario, resultan inaplicables, esto, en virtud de que con ello el legislador local restringe sin justificación alguna el derecho relativo al desarrollo de la personalidad humana, que tiene que ver con la libre modificación del estado civil de las personas que deriva (libertad de seguir unido en matrimonio), y a su vez del derecho fundamental a la dignidad humana consagrado 
en los tratados internacionales de los que México es parte y que han quedado precisados en líneas que anteceden, máxime que dicha disposición contrasta con los artículos 1o. y 4o. de la Constitución Federal, conforme al cual las personas tienen derecho a elegir, en forma libre y autónoma, su proyecto de vida, en el que se comprende precisamente el estado civil en que deseen estar.

Y en el caso concreto del presente artículo, como se ha señalado en las diversas tesis, así como en la tesis "XVIII.4o.10 C (10a.), Décima Época, Gaceta del Semanario Judicial de la Federación, Libro 2, Enero de 2014, Tomo IV, Página: 3050, Registro IUS número 2005338, con el rubro siguiente: DIVORCIO. EL ARTÍCULO 175 DEL CÓDIGO FAMILIAR PARA EL ESTADO LIBRE Y SOBERANO DE MORELOS, AL EXIGIR LA DEMOSTRACIÓN DE DETERMINADA CAUSA PARA LOGRAR LA DISOLUCIÓN DEL VÍNCULO MATRIMONIAL, CUANDO NO EXISTE CONSENTIMIENTO MUTUO, ES INCONSTITUCIONAL AL RESTRINGIR EL DERECHO AL DESARROLLO DE LA PERSONALIDAD HUMANA"; los numerales 272 del Código Civil, 501 y 505 del Código Procesal civil anteriormente citados, al exigir el acreditamiento de causas y condiciones para disolver el vínculo matrimonial, restringen el derecho a la libertad que tienen los cónyuges de permanecer o no unidos en matrimonio.

\section{Propuesta}

Por lo que, se llega a la plena conclusión en el presente artículo, que se deberá considerar o tomar en cuenta que basta la exposición libre que uno de los cónyuges haga ante el tribunal competente en no seguir unido en matrimonio, para declarar la disolución del vínculo matrimonial; sin necesidad de probar los elementos que constituyen la causal alegada en el artículo 272 del Código Civil en vigor en el Estado de Tabasco, y sin que prospere en los juicios de divorcio necesario ninguna excepción alegada por el otro cónyuge respecto a la disolución del vínculo matrimonial.

\section{DISCUSIÓN}

Por lo que, es de manifestar que los artículos 272 del Código Civil, 501 y 505 del Código de Procedimientos Civiles ambos ordenamientos vigente en el Estado, al exigir la demostración de determinada causa de divorcio como única forma para lograr la disolución del vínculo matrimonial, cuando no existe consentimiento mutuo de los contrayentes para divorciarse, y establecer que el divorcio solo podrá demandarse por el cónyuge que no haya dado causa a él y que deberá tramitarse conforme a las reglas establecidas para el juicio ordinario, resultan inaplicables, esto, en virtud de que con ello el legislador local restringe sin justificación alguna el derecho relativo al desarrollo de la personalidad humana, que tiene que ver con la libre modificación del estado civil de las personas que deriva (libertad de seguir unido en matrimonio), y a su vez del derecho fundamental a la dignidad humana consagrado en los tratados internacionales de los que México es parte y que han quedado precisados en líneas que anteceden, máxime que dicha disposición contrasta con los artículos 1o. y 4o. de la Constitución Federal, conforme al cual las personas tienen derecho a elegir, en forma libre y autónoma, su proyecto de vida, en el que se comprende precisamente el estado civil en que deseen estar. 


\section{REFERENCIAS}

1. Código Civil del Estado de Tabasco, publicado en el suplemento del periódico oficial del Estado de Tabasco, 9 de abril de 1997.

2. Constitución Política de los Estados Unidos Mexicanos.

3. Tesis Jurisprudencial número IV.2o.A. J/7 (10a.), Décima Época, Gaceta del Semanario Judicial de la Federación, Libro 1, Diciembre de 2013, Tomo II, Página: 933, Registro IUS número 2005056

4. Congreso del Estado de Tabasco. (1997). Código de Procedimientos Civiles en vigor del Estado de Tabasco.

5. Corte Interamericana de Derechos Humanos. (2012). Caso Fornerón e Hija Vs. Argentina. (CIDH, 27/4/2012). Costa Rica.

6. Organización de los Estados Americanos. (1969). Convención Americana sobre Derechos Humanos. Departamento de Derecho Internacional, Secretaría de Asuntos Jurídicos: Costa Rica.

7. Tesis P. LXX/2011 (9a.), Décima Época, Semanario Judicial de la Federación y su Gaceta, Libro III, Diciembre de 2011, Tomo 1, Página: 557, Registro IUS número 160480 